ANL -5072

Instrumentation

ARGONNE NATIONAL LABORATORY

P. O. Box 299

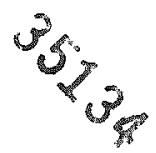

Lemont, Illinois

\title{
A METHOD FOR STABILIZING SCALING CIRCUITS \\ by
}

Jerome L. Lerner

\section{CHEMISTRY DIVISION}

June 5,1953

Operated by The University of Chicago

under

Contract $W-31-109$-eng -38 


\section{DISCLAIMER}

This report was prepared as an account of work sponsored by an agency of the United States Government. Neither the United States Government nor any agency Thereof, nor any of their employees, makes any warranty, express or implied, or assumes any legal liability or responsibility for the accuracy, completeness, or usefulness of any information, apparatus, product, or process disclosed, or represents that its use would not infringe privately owned rights. Reference herein to any specific commercial product, process, or service by trade name, trademark, manufacturer, or otherwise does not necessarily constitute or imply its endorsement, recommendation, or favoring by the United States Government or any agency thereof. The views and opinions of authors expressed herein do not necessarily state or reflect those of the United States Government or any agency thereof. 


\section{DISCLAIMER}

Portions of this document may be illegible in electronic image products. Images are produced from the best available original document. 
A METHOD FOR STABILIZING SCALING CIRCUITS

by

Jerome L. Lernex

SUMMARY

The stability of a circuit exhibiting more than one stable state can be improved through the use of nonlinear silicon carbideresistors. With theseresistors, vacuum tube life expectancy in scaling and computing circuits can be increased considerably.

The stability of a scaling stage can be considerably improved through the use of certain nonlinear resistors in the plate-to-grid coupling circuits. This substitution is simple and inexpensive, ye greatly extends the life expectancy of the tubes normally used in scalers. Alternatively, this modifica tion permits increasing the speed of a binary scaler for the same vacuum tube life expectancy.

Figure $1 \mathrm{a}$ is typical of the commonly used binary scaling circuits. A complete description of the operation of this scaler is available from many sources. 1,2,3 Normally, one tube is conducting while the other tube is cut off. This condition is stable provided that the bias on the nonconducting tube is sufficient so that the over-all gain of the scaler, considered as a two-stage feedback amplifier, is less than unity. One of the most common causes of tube failure in this circuit is decrease of emission in either or both triodes: $i_{\circ} e_{\circ}$ one tube cannot draw enough current through its plate resistor (and thus lower the plate voltage sufficiently) to adequately cut off the other tube.

It should be noted that even with a very weakly emitting tube, the change in plate voltage would be enough to cut off the other tube if the entixe plate voltage shift could be applied to the opposite grid. For example, the

1W. C. Elmore and M. Sands, Electronics Experimental Techniques (McGraw-Hill Book Co., Inc. New York, 1949), p. 208.

2B. E. Phelps, "Dual-Triode Trigger Circuits," Electronics, Vol.18, No. 7, 110 (Tuly, 1945).

${ }^{3}$ B. Chance, et al, Waveforms, M. I. T. Radiation Laboratory Series, 19 (McGraw-Hill Book Co., New Yoxk, 1949), p.604. 
plate voltage change from nouconducting to full conduction is about 115 volts for a normal tube drawing abowt 6.5 milliamperes (Figure la). With a weak tube, which may deliver no more than possibly 2.5 millamperes, the plate voltage swing is only 50 volts. This would be sufficient to cut of the opposite tube if it could be applied to the grid without atteruation. The plate voltage swing is reduced to abour one-third $(0.11 / 0.11+0.24=0.315$ in Figure la) by the plate to-grid resistor divider coupling, so that the woltage change applied to the grid in the later case is less thar 16 volls. A minimum of 20 volts bias is required to maintain a stable state.

By using certain nonlimear resistors in place of $R_{2}$, if ${ }^{\prime}$ possible to transfer a larger fraction of the plate woltage change to bhe opposite grid (Figure 1b). These resistors, which are made with silicon carbide (Sic) and are avablable under vious lrade names" have a characteristic of the form

$$
R=K E^{-n} \text { or } I=\frac{1}{K} E^{n+1}
$$

(Figuxe 2).

The exponent "n" varies from 2.5 to as much as 6 , depending upon the method of manufacture. A value of three is typical. So far as is known, change of resistance with voltage does not involve any time lag. From "load limes" similar to those ofter used for vacumm tube analysis it is evident that these resistors, when used with a series linear resistor, tend to stabilize the voltage across thenselves (Figure 2). For example, a $40 \%$ change in supply voltage is reduced to $18 \%$ change across the SiC resisto

The improvenent effected by using the nonlinea resistors is readily determined from the curves in Figure 3. With a linear $240 \mathrm{~K}$ sesistor in series with a $110 \mathrm{~K}$ grid resisto the grid voltage changes from 74 volts to 38 volts as the plate voltage varies from 235 to 120 volts (Figure 32 ). With the ponlinea resistor in series with the same grid resistor and with the same change in plate potential, the grid swings from 72 to 14 volts (Figure $3 b$ ). With the later circuit the tube need draw only 3.5 millamperes (dropping the plate voliage to about 175 volts) in order to give the same shift in grid voltage as does the circuit using linear components ard a normal tube.

The circuits shown in Figures la and 1 b were constructed with closely matched components in ordex to test empirically the relative merits of the latter circuit. The circuits are identical except for the SiC resistors used in place of the $240 \mathrm{~K}$ platem to gxid coupling resistors. Expeximents were conducted in which the plate resistors. grid resistors, and cathode resistors were altered until the first circuit failed to scale properly. In every case the same

*Thyrite" (General Electic), "Vasso" (Western Electric). "Type $\mathrm{BNR}^{*}$ (Carborundum Co.) 
tube in the nonlinear circuit using corresponding components continued to operate reliably. In most cases the changes that disabled circuit la had to be considerably increased in order to affect circuit $1 \mathrm{~b}$ seriously. The most striking difference in behavior occurred with optimum resistors and con densers: but using racum tubes that had undergone extensive use. Out of a batch of $10012 \mathrm{AUT}$ 's that had been rejected for various reasons after long - service, there $\mathrm{w}$ ere 16 that did not function at all in circuit la. Every one of these tubes scaled successfully in circuit $1 \mathrm{~b}$, even though the emission in some cases was so low as to give a reading of less than 100 micromhos in both sections on a conventional tube checker. Since cathode interface ef fects are particularly troublesome in scalers.4 it is interesting to note that the nonlinea circult operated properly with as much as $5 \mathrm{~K}$ inserted between one cathode and the $10 \mathrm{~K}$ cathode resistor.

Nonlinear esistors can be profitably applied to other circuits employing direct plate-to-grid coupling. In a texnary or wing-of-three scaling circuit, for example, each grid might be connected to the plates of two other tubes through appropriate $x$ esistors $\mathrm{F} 1 \mathrm{~g} \cdots 3=$ i, For proper operation, $\mathrm{T}_{1}$ should be conducting when both $T_{2}$ and $T_{3}$ are cutoff but $T_{1}$ should be cut off when either $T_{2}$ or $T_{3}$ is conducting. Design of this circuit is more dif ficult than design of a binary scaler. since the plate voltage swing available to the grid is effectively halved because of the connection to the nonconducting tube. With one plate held fixed at 228 volts, the grid goes from 86 to 64 volts as the other plate varies from 228 to 110 volts (Figure $4 a$ ). With a nonlinear fesistor in the coupling circuit, the grid voltage changes from 86 to 52 volts for the same plate voltage shift (Figure $4 b$ ). Simila considera tions hold for scaling rings of higher order.

The nonlinear resistors should be particularly useful in fast scaling circuits where tube failures are relatively frequento In fast circuits the plate voltage swing is generally limited. either through the use of smaller plate resistors or deliberately through the use of diode clamps. $1,3,5$ In such cases a more efficient platemtomgrid coupling is very desizable.

4J. R. Weymouth, Ir。, J. App1. Phys. 22, 80 (1951).

${ }^{5} \mathrm{~A}$. S. Bagley, "A $10 \mathrm{Mc}$ Scaler for Nuclear Counting and Frequency Measurement," Hewlitt-Packard Journal 2, No.2 (October 1950). 


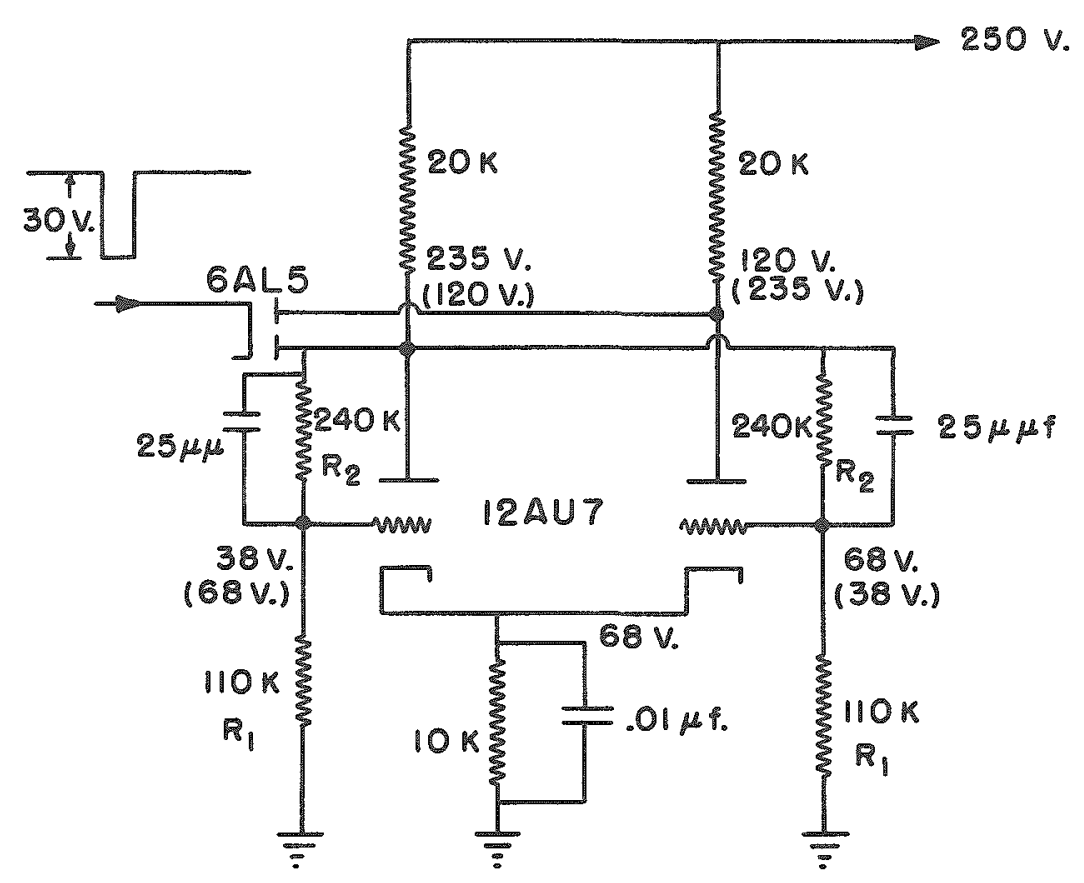

(a)

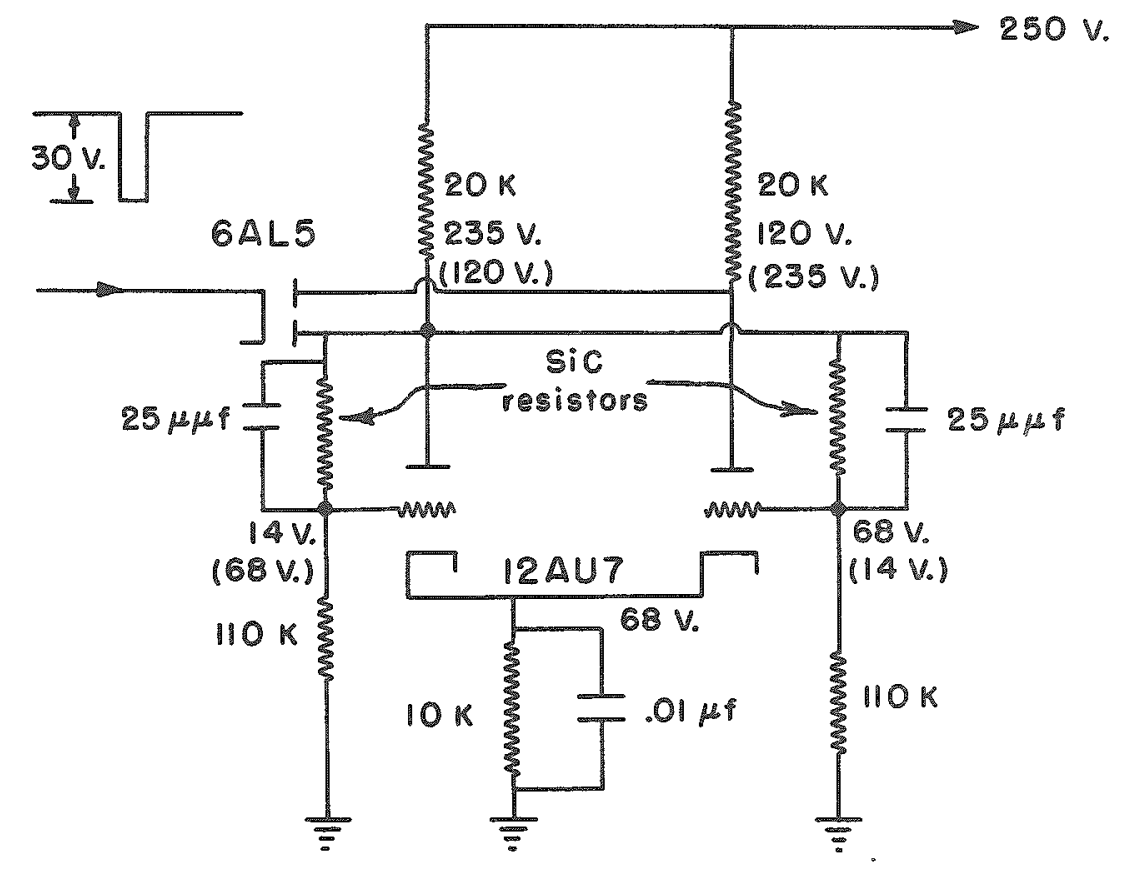

(b)

FIGURE 1 .

TYPICAL BINARY SCALER (a) MODIFIED (b) FOR INCREASED RELIABILITY. 


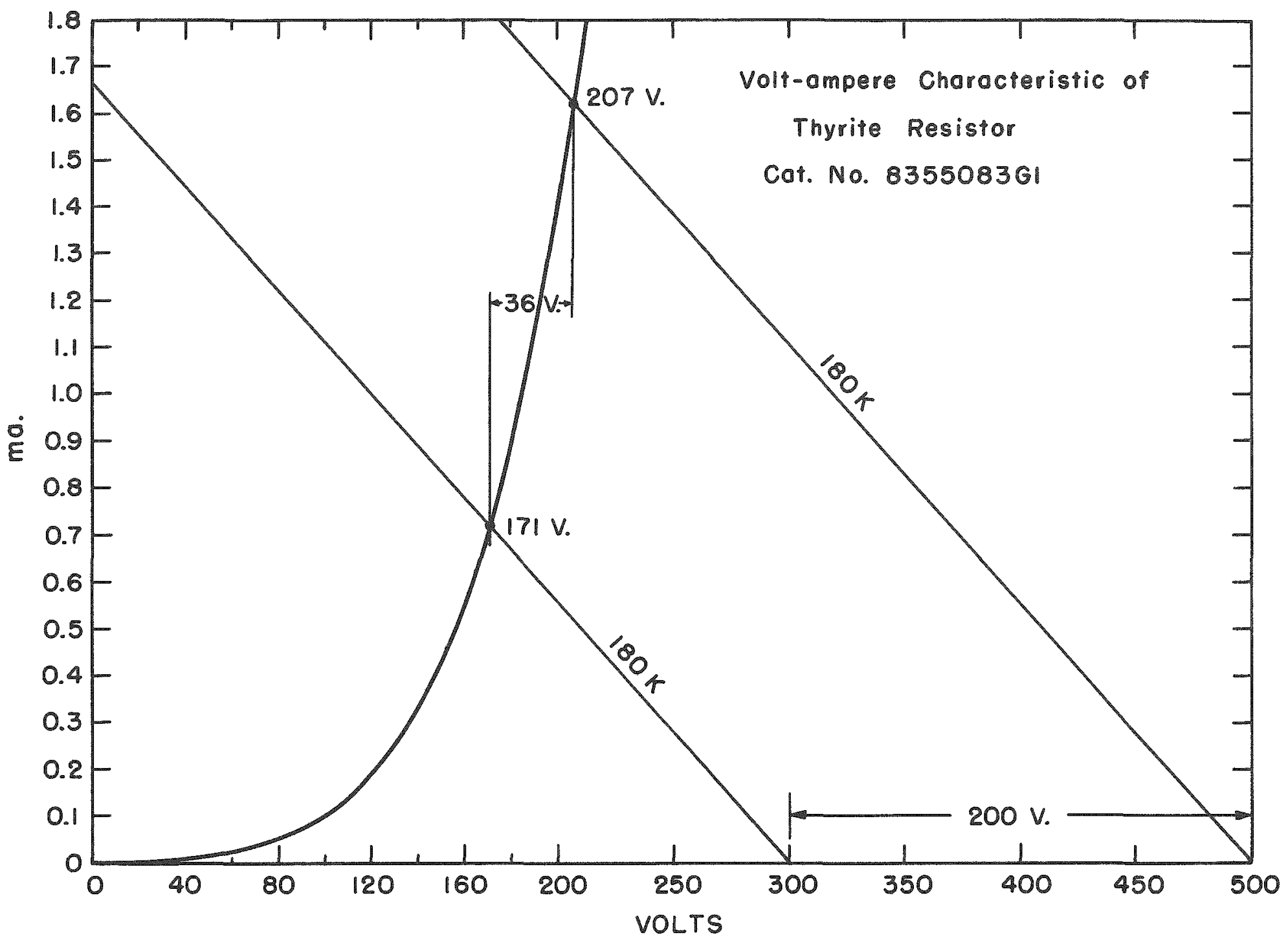

FIGURE 2.

I-E CHARACTERISTIC OF NON-LINEAR RESISTORS. 


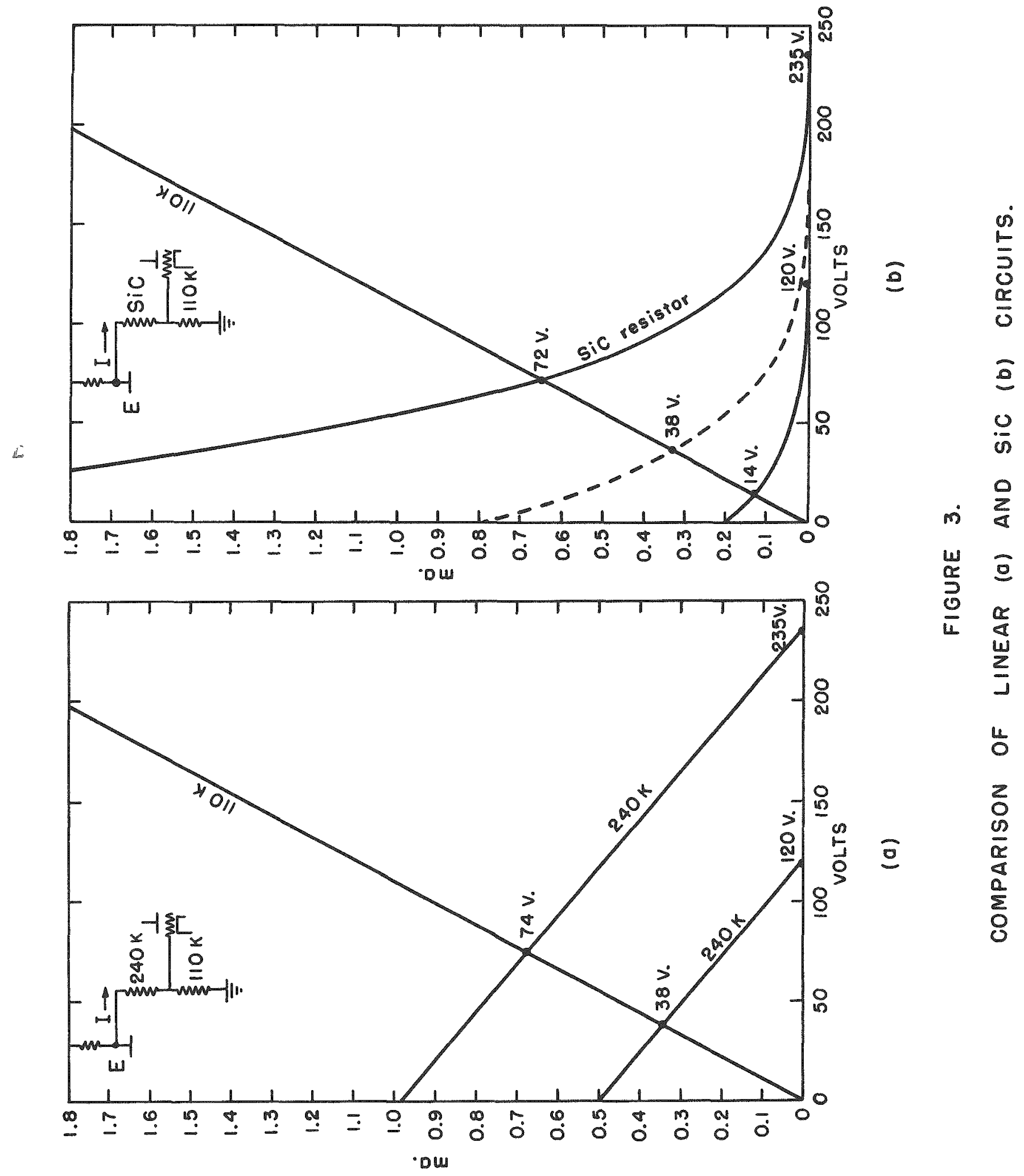




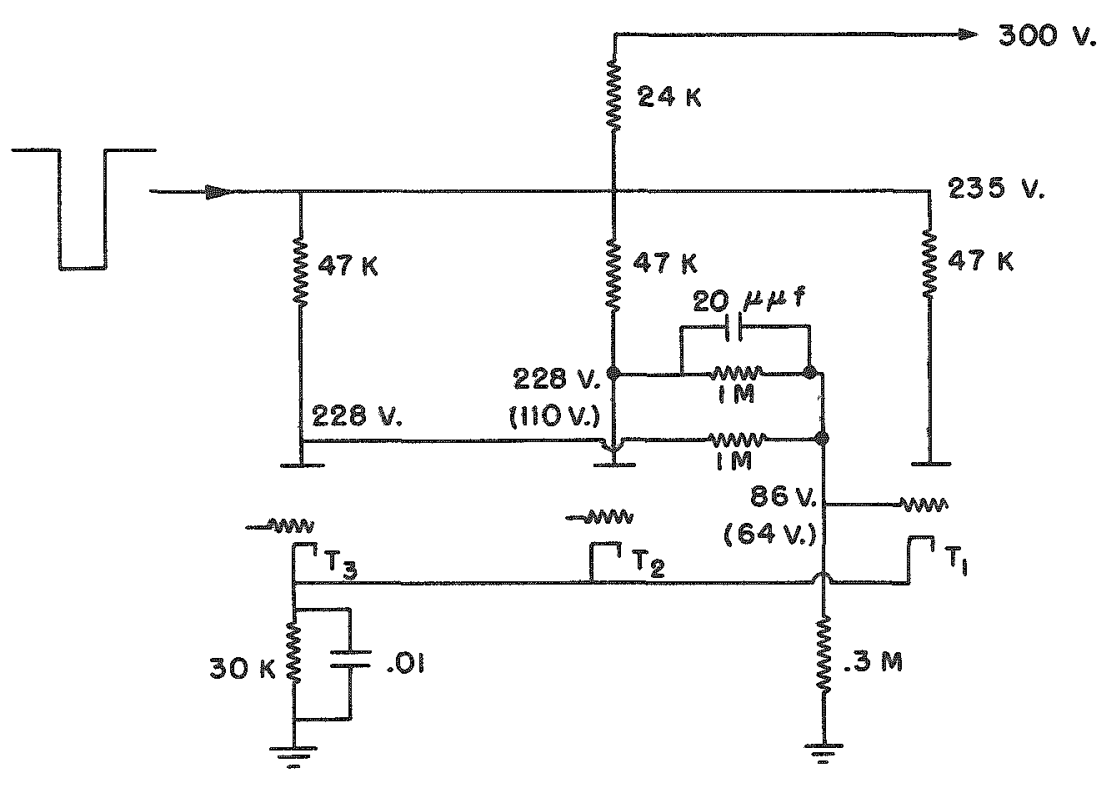

(a)

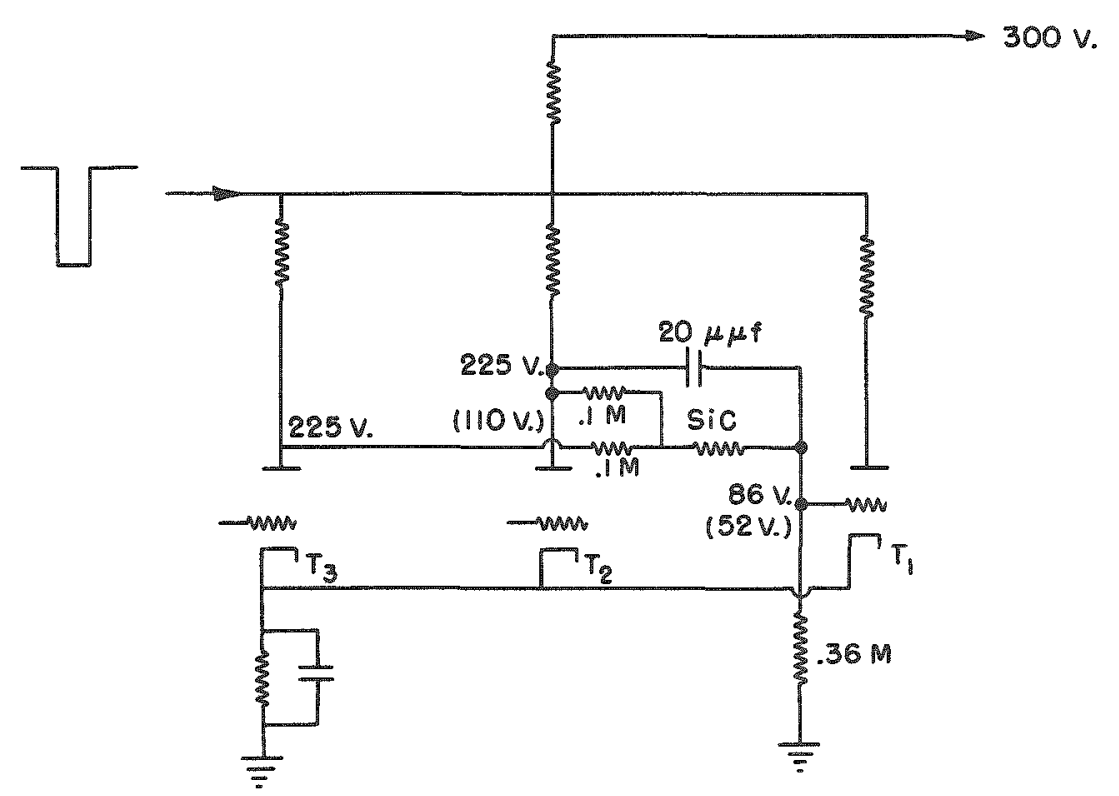

(b)

FIGURE 4.

PARTIAL SCHEMATIC OF TERNARY SCALER (O) MODIFIED FOR GREATER STABILITY $(b)$. 